\title{
Experiências da escravidão e formação de comunidades quilombolas no Paraná
}

\author{
Frank Mezzomo \\ Doutor em História Cultural (Universidade Federal de Santa Catarina) \\ Professor da Faculdade Estadual de Ciências e Letras de Campo Mourão \\ Campo Mourão, Brasil \\ frankmezzomo@gmail.com \\ Roselene Semprebom \\ Professora no Núcleo Regional de Eduacação de Goioerê \\ Goioerê, Brasil \\ lenesfreire@hotmail.com
}

\begin{abstract}
Resumo Neste artigo são analisadas duas comunidades quilombolas localizadas na região de Castro e Ivaí, no interior do estado do Paraná, no que diz respeito à experiência da escravidão, ao processo de formação e à situação atual de cada uma delas. Para execução da pesquisa, além da visitação in loco, foram utilizadas fontes primárias (entrevistas e fotografias) e pesquisa bibliográfica. Em paralelo, apresentam-se alguns resultados de trabalho desenvolvido com estudantes do Ensino Fundamental, no intuito de contemplar a temática da cultura afro-brasileira no currículo, em conformidade com a Lei Federal n. 10.639/2003. A intervenção pedagógica ocorreu em uma escola pública localizada no município de Janiópolis/PR, com base em material didático elaborado a partir dos dados obtidos pela investigação.
\end{abstract}

Palavras-chave: escravidão, comunidades quilombolas, Paraná.

\section{Introdução}

\begin{abstract}
O resgate da memória coletiva e da história da comunidade negra não interessa apenas aos alunos de ascendência negra. [...] Além disso, essa memória não pertence somente aos negros. Ela pertence a todos, tendo em vista que a cultura da qual nos alimentamos cotidianamente é fruto de todos os segmentos étnicos que, apesar das condições desiguais nas quais se desenvolvem, contribuíram cada um de seu modo na formação da riqueza econômica e social e da identidade nacional. (Kabengele Munanga)
\end{abstract}

$\mathrm{E}$

ste artigo propõe-se a compreender algumas experiências históricas ¿da escravidão e a formação e situação atual em que se encontram duas comunidades quilombolas no Paraná, formadas ainda no século XIX. A reflexão está inserida no contexto da Lei Federal n. 10.639, de 09 de janeiro de 2003, que tornou obrigatória a inclusão do ensino da cultura africana e afro-brasileira nos currículos escolares, como parte de ação afirmativa voltada a induzir uma prática de reconhecimento e valorização das raízes africanas na sociedade brasileira, que por muitos séculos foram estigmatizadas. Parte da historiografia brasileira, sobre- 
tudo até meados da década de 1980, deu ênfase a uma reflexão voltada para uma cultura europeizada, negligenciando a participação e contribuição de outras matrizes culturais na constituição histórica do Brasil.

Entre os séculos XVII e XIX, o Paraná atraiu e absorveu parte da mão de obra e da cultura de grupos humanos que, na condição de escravos, foram traficados do Continente Africano. Conduzidos para América, sob extrema violência e precárias condições de sobrevivência nos porões de navios negreiros, constituíram uma das principais forças produtivas do estado paranaense desde o setecentos.

Após proclamação da Lei Áurea em 1888, parte significativa dos egressos da escravidão secular esteve envolvida na celeuma da discriminação racial, a reboque das teorias racialistas dos séculos XIX e XX, ${ }^{1}$ além da não aceitação no mercado de trabalho por falta de amparo constitucional. A instrumentalização da violência como mecanismo de ordenamento social (Lima, 2002) e experiências de lutas e resistências marcaram a incorporação de inúmeras etnias negras ao sistema colonial brasileiro.

Talvez tributário da experiência histórica da escravidão e do preconceito racial, pode-se afirmar que essa temática ainda é marginal, inclusive para a historiografia contemporânea, quando trabalha a questão da ocupação e colonização do Paraná. Neste sentido, livros e mesmo outros veículos de comunicação, como jornais e demais informativos, priorizam e tratam da migração europeia como epopeia que, ao longo dos séculos XIX e XX, desbravaram os rincões e produziram riqueza no estado do Paraná.

Assim, a fim de compreender a formação e as condições de existência das comunidades quilombolas é que se propôs, mediante discussão bibliográfica e visitação in loco, problematizá-las. A investigação subsidiou ainda a produção de material didático, conforme orientação da Secretaria de Estado da Educação, ${ }^{2}$ com o objetivo de trazer para o âmbito escolar as discussões desenvolvidas pelos professores vinculados ao Programa de Desenvolvimento Educacional (PDE).

Antes de apresentar os resultados da pesquisa realizada, faz-se uma pequena digressão, a fim de con- textualizar a elaboração do material de intervenção pedagógica, concebido entre abril e junho de 2010 e trabalhado com os estudantes da Educação Básica nos meses de agosto a dezembro do mesmo ano. ${ }^{3}$

Para a elaboração da proposta de intervenção pedagógica, realizou-se uma revisão bibliográfica em livros e artigos, a fim de compreender o processo histórico da escravidão no Paraná, e, como um dos objetivos era a visitação in loco em comunidades quilombolas, preparar-se teórica e metodologicamente para realizar a pesquisa de campo. Essa preparação inicial tornou-se importante para a elaboração do material didático.

O material didático, com pouco mais de setenta páginas, teve a forma de Unidade Didática ${ }^{4}$ e se constituiu de 10 capítulos, que tematizaram a escravidão e a formação de comunidades quilombolas no estado do Paraná. Para a produção do material, utilizaram-se pequenos textos para compreensão do objeto estudado, junto com atividades de reflexão e discussão de alguns acontecimentos referenciais. Utilizaram-se recursos imagéticos, como fotos, mapas, além da indicação de recursos sonoros, como músicas, trailers de filmes, entre outros, a fim de despertar o interesse e, sobretudo, representar o conteúdo estudado numa linguagem próxima ao universo dos estudantes.

A intervenção pedagógica, realizada com base no material didático produzido, teve a finalidade de proporcionar aos estudantes a formação de conhecimentos científicos, de conteúdos e conceitos específicos, com vistas a um aprendizado sobre a cultura e as experiências históricas dos povos africanos e afro-brasileiros. Conforme sugeria o material didático, no transcorrer das aulas realizadas no segundo semestre de 2010 utilizaram-se atividades expositivas e dialogadas; trailer de filmes e documentários; estudos de textos, documentos e narrativas; interpretação de poemas, músicas, mapas e figuras; confecção de desenhos; apresentação de seminários e relatórios elaborados pelos estudantes.

\footnotetext{
1. Entre inúmeras pesquisas que historicizam os debates racialistas, sobretudo nos séculos XIX e XX, consultar o interessante estudo da antropóloga Lilian Moritz Schwarcz (1993).
}

2. O Programa de Desenvolvimento Educacional da Secretaria de Estado da Educação do Paraná (PDE/PR) estabelece que o professor vinculado ao Programa desenvolva atividades como estudo e leituras orientadas, bem como produza materiais paradidáticos. Entre os materiais desenvolvidos por esta pesquisa consta a montagem de Material Didático utilizado durante a intervenção pedagógica com uma turma da Educação Básica. A finalidade do material, utilizado inicialmente pelo professor PDE, é servir de suporte pedagógico a ser utilizado pelos professores e equipe pedagógica da escola.

3. O material de Intervenção Pedagógica foi trabalhado com turmas de 6a série da Escola Estadual Dom Pedro II, localizada no município de Janiópolis/PR.

4. Entende-se por Unidade Didática o material composto por abordagem de uma única unidade de um mesmo tema, contendo texto de fundamentação e as respectivas atividades a serem desenvolvidas (Cf. Orientações sobre o projeto de Intervenção Pedagógica na Escola, Secretaria de Estado da Educação - Superintendência de Educação. Coordenação Estadual do PDE. Curitiba, 2008). 


\section{Pesquisando quilombos paranaenses}

O contato direto com as comunidades quilombolas permitiu melhor compreensão das experiências históricas da escravidão vivenciadas desde o século XVIII, assim como a coleta de informações sobre a formação e o estado atual das comunidades. Convém destacar que a opção por realizar a pesquisa in loco teve ainda como motivação a escassez de materiais sobre a história das comunidades quilombolas no estado do Paraná, já que a literatura contemporânea é ainda incipiente sobre essa temática. Outro fator que desencadeou a motivação da visita foi a possibilidade de compreender como atualmente as comunidades quilombolas estão organizadas e estruturadas: espaços de convivência, serviços de saneamento básico, educação, religiosidade, entre outros.

Grande parte dos remanescentes da escravidão no estado do Paraná vive em comunidades quilombolas. No entendimento de Glória Moura (1999, p. 100), podem-se definir quilombos contemporâneos como comunidades negras rurais habitadas por descendentes de escravos que mantêm laços de parentesco e vivem, em sua maioria, de culturas de subsistência, em terras doadas, compradas ou ocupadas secularmente pelo grupo. $\mathrm{Na}$ avaliação de Santos (2009) e Anjos (2010), a formação de comunidades quilombolas, constituídas por grupos étnicos negros livres ou fugitivos, ocorreu em diferentes tipos de terras, tais como em áreas da união e indígenas e

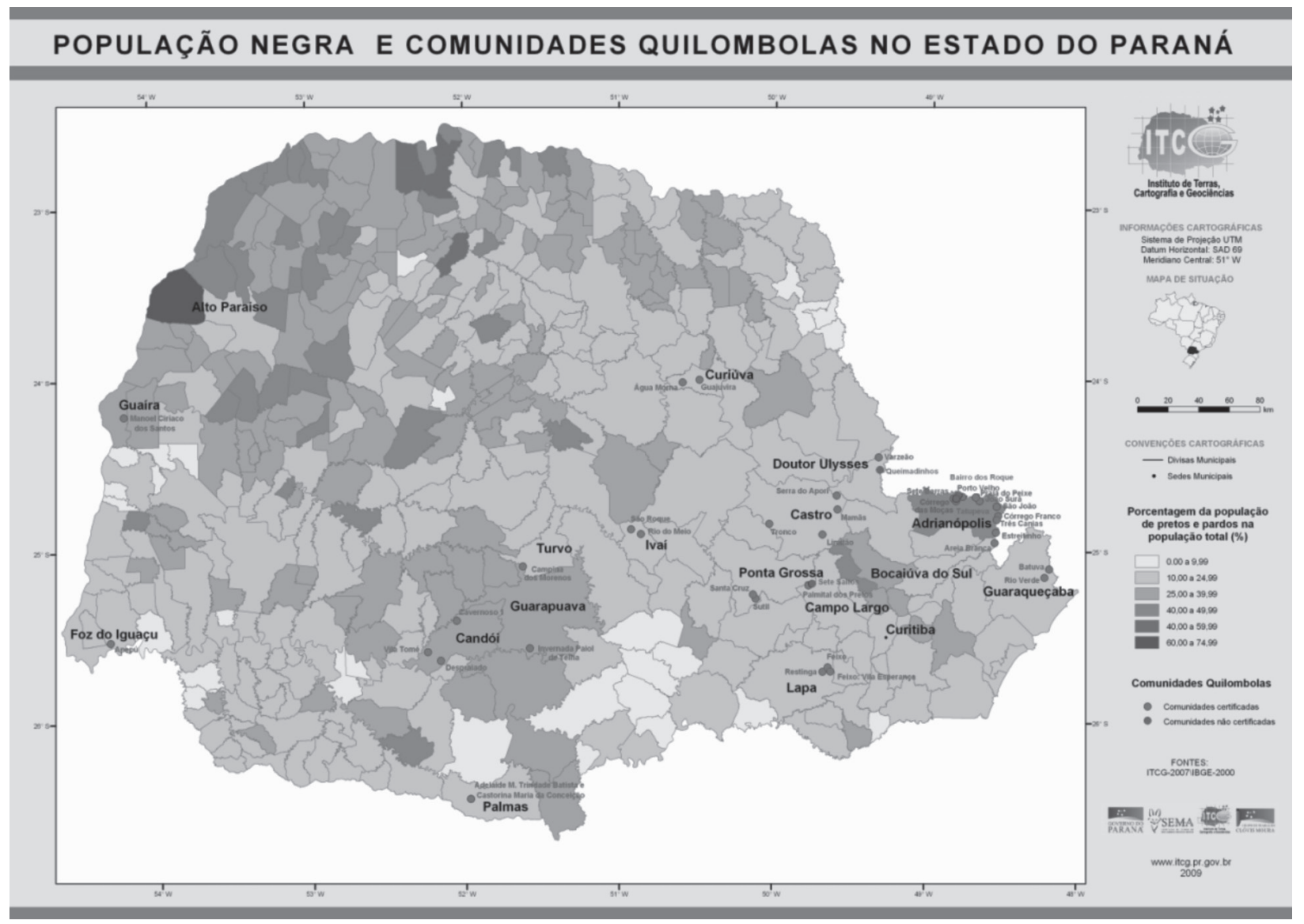

Figura 1 - População negra e comunidades quilombolas no estado do Paraná Fonte: Disponível em: $<$ http://www.diaadia.pr.gov.br/nerea/modules/noticias $/$ makepdf.php?storyid=28> Acesso em: 20 fev. 2013

5. A Fundação Cultural Palmares é uma entidade pública vinculada ao Ministério da Cultura cujo objetivo corporifica os preceitos constitucionais de reforços à cidadania, à identidade, à ação e à memória dos segmentos étnicos dos grupos formadores da sociedade brasileira. Para demais informações sobre a Fundação, consultar: http://www.palmares.gov.br

6. Consideram-se comunidades remanescentes de quilombos os grupos étnicos raciais, segundo critérios de autoatribuição, com trajetória histórica própria, dotados de relações territoriais específicas, com presunção de ancestralidade negra relacionada com formas de resistência à opressão histórica sofrida. Já o conceito de comunidades negras tradicionais é mais amplo. São grupos culturalmente diferenciados e que se reconhecem como tais, que possuem formas próprias de organização social, que ocupam e usam territórios e recursos naturais como condição para sua reprodução cultural, social, religiosa, ancestral e econômica, utilizando conhecimentos, inovações e práticas gerados e transmitidos pela tradição. Nele podem ser englobados, por exemplo, os próprios quilombolas; os terreiros de matriz africana; as comunidades negras rurais que não detêm modo de vida próprio de comunidades quilombolas; os povos indígenas etc. Disponível em: <http://www.palmares.gov. br/108/10802002.jsp?ttCD_CHAVE=51>. Acesso em: 05 jan. 2013. 
naquelas herdadas dos antigos donos, além de terras compradas pelos escravos alforriados, abandonadas ou de propriedade desconhecida. Assim se constituiu o espaço geográfico quilombola, palco contemporâneo de conflitos fundiários.

Na visão de Ruy Wachowicz (2002), o Paraná do século XVIII, tomado por sertão bruto e cheio de matas, servia de esconderijo para os negros fugitivos de São Paulo, do próprio local e dos núcleos de Curitiba e litoral paranaense. Continua o historiador afirmando que "os capões e furnas dos Campos Gerais também se tornaram locais de esconderijo de foragidos da lei, que regularmente eram designados como galafreses" (p. 81). A despeito desses fatos e acontecimentos, havia no Paraná, na metade do século XIX, quilombos constituídos nessas terras. Algumas comunidades ainda se encontram em seus locais de formação original, com suas culturas e costumes específicos, e outras foram extintas, por exemplo, a Comunidade Sam Damas, localizada onde hoje é o município de Tibagi, pertencente à Mesorregião Centro Oriental Paranaense.

Existem no Paraná 34 comunidades quilombolas identificadas e certificadas pela Fundação Cultural Palmares $^{5}$, como mostrado na Figura 1. Diante disso, optou-se por investigar quatro comunidades, a saber: Comunidade Remanescente de Quilombo Serra do Apon, no município de Castro; Comunidade Negra Tradicional do Bairro São Roque, no município de Ivaí; Comunidade Remanescente de Quilombo Invernada Paiol de Telha (assentamento), no município de Guarapuava; e, finalmente, a Comunidade Remanescente de Quilombo Campinas dos Morenos, no município de Turvo. ${ }^{6} \mathrm{O}$ critério para a escolha e a quantidade de quilombos a serem pesquisados foi, basicamente, de logística e viabilidade financeira, assim como o período disponível para execução da investigação. Embora a pesquisa tenha sido realizada nas quatro comunidades, em razão do espaço, neste artigo serão discutidas apenas a comunidade Serra do Apon, localizada no município de Castro, e a comunidade Bairro São Roque, em Ivaí. As duas comunidades estão localizadas na Mesorregião Centro Oriental Paranaense.

Para subsidiar a pesquisa, foi elaborado um questionário prévio, a partir de questões que se pretendia investigar: formação histórica da comunidade; localização e descrição do espaço e da paisagem; sistema atual de transporte, educação formal e produção econômica; culinária, festas e religiosidade. No decorrer da pesquisa, outros aspectos foram acrescentados, mediante o relato dos entrevistados e das condições observadas.

De maneira geral, as comunidades encontram-se em locais de difícil acesso, com estradas íngremes, estreitas, tomadas por buracos, pedras soltas, poeiras em períodos quentes e lamaçais em épocas chuvosas. A ausência de placas de sinalização dificulta o acesso às comunidades quilombolas, sendo indicado o uso de mapas rodoviários, do Sistema de Posicionamento Global (GPS) e das tradicionais informações dos transeuntes.

Munidos de gravador, câmera fotográfica, prancheta de anotações e de um roteiro de perguntas semiestruturadas, buscou-se captar o sentido e o significado das experiências relatadas pelos moradores dos quilombos. Assim, as informações coletadas tratam de impressões captadas das comunidades, como as suas histórias, suas necessidades básicas, suas reivindicações e a problemática e polêmica questão do direito à terra.

Foi possível perceber, nas entrevistas e nos relatos, as experiências e vivências do grupo social que integra essas comunidades, que mesmo distantes de outras comunidades quilombolas carregam comportamentos socioculturais semelhantes. Percebe-se que nesses espaços a história e a memória estão presentes nas experiências e manifestações culturais que os mais antigos repassam, também herdados de geração anterior.

Em suma, pode-se dizer que a pesquisa in loco conseguiu explorar alguns conteúdos e discussões já apresentados nos meios acadêmicos e produções bibliográficas sobre as populações negras, confirmando-os, complementando-os e, às vezes, relativizando-os mediante a formulação de outras perguntas e outros olhares.

É perceptível, pelas informações colhidas e entrevistas feitas nas referidas comunidades quilombolas, a bandeira da necessidade de reaver a posse das terras que foram espremidas pela especulação imobiliária, pelo agronegócio e por assentamentos promovidos pelo governo. Tais situações criadas historicamente geram profundas fissuras nos modos de viver e nas práticas culturais dos negros, daí que a conservação do espaço territorial quilombola é fato preponderante e referencial para a preservação de suas tradições. No que tange às comunidades paranaenses pesquisadas, é recorrente a reivindicação da reconquista da terra como possibilidade de proteção do patrimônio cultural e da afirmação da identidade afrodescendente.

A demora de órgãos oficiais do governo em reconhecer a propriedade de terras das comunidades quilombolas tem dificultado a implantação de políticas que suavizem as condições de vida, o que provoca sofrimento pela angústia de terem sidos expropriados do quinhão a que tinham direito, mesmo nas condições em que, ingenuamente ou não, cederam suas posses. Nesse contexto, a afirmação de Santos (2009) reforça o entendimento de exploração a que estão submetidas as comunidades quilombolas, quando afirma que muitas 
não são sequer reconhecidas pelo poder público, mesmo aquelas que já o são, não estão conseguindo com facilidade a titulação de suas terras e propriedades. Este processo está bastante moroso em função do jogo político e dos interesses econômicos presentes no campo, vinculados ao poder local, as artimanhas burocráticas associadas ao não registro em cartório destas áreas ocupadas a séculos pelos negros. (p. 145)

No entendimento de Miriam Chagas (2001), o Brasil é dos poucos países que não resolveu formalmente a questão dos direitos territoriais das comunidades negras tradicionais.

\section{Comunidade Remanescente de Quilombo Serra do Apon}

A comunidade negra rural Serra do Apon localiza-se no município de Castro, distante $60 \mathrm{~km} \mathrm{da}$ cidade. $\mathrm{O}$ acesso ao quilombo é por estrada de chão batido e parte de cascalhos. Segundo relatos dos moradores da região, o local era habitado por indígenas Abapanis quando negros fugitivos da Fazenda Capão
Alto chegaram ao local. Preferiram os lugares mais inóspitos e de difícil acesso, com mata serrada para refugiar-se e não serem descobertos. Assim, escolheram locais conhecidos hoje como Serra do Apon, Limitão e Mamans.

Segundo relato de Vani Rodrigues dos Santos, ${ }^{7}$ bisneta de Prudente Rodrigues da Silva, o Quilombo Serra do Apon foi formado pelo seu bisavô e por Ambrósio da Trindade, que se casou com uma índia do lugar. Os ancestrais dos que habitam a Serra do Apon viviam livres na Fazenda Capão Alto, situada próxima à cidade de Castro.

A referida fazenda fazia parte da primeira Sesmaria dos Campos Gerais do Capitão-mor José de Góes e Moraes, que a vendeu, em 1751, ao Convento do Carmo de São Paulo. Em 1770 os Carmelitas retiraram-se do Paraná, deixando por conta dos escravos a fazenda Capão Alto, tendo como administrador o escravo de alcunha Innocêncio Não Foge. Gozando de total liberdade, os negros viviam em uma república independente, um quilombo, nas ricas terras dos Carmelitas (Cadernos do Patrimônio, 1982, p. 26).

Com grande devoção a Nossa Senhora do Carmo, chamada por eles de "Sinhara", a ela se reportavam para tudo quanto fosse necessário, pediam orien-

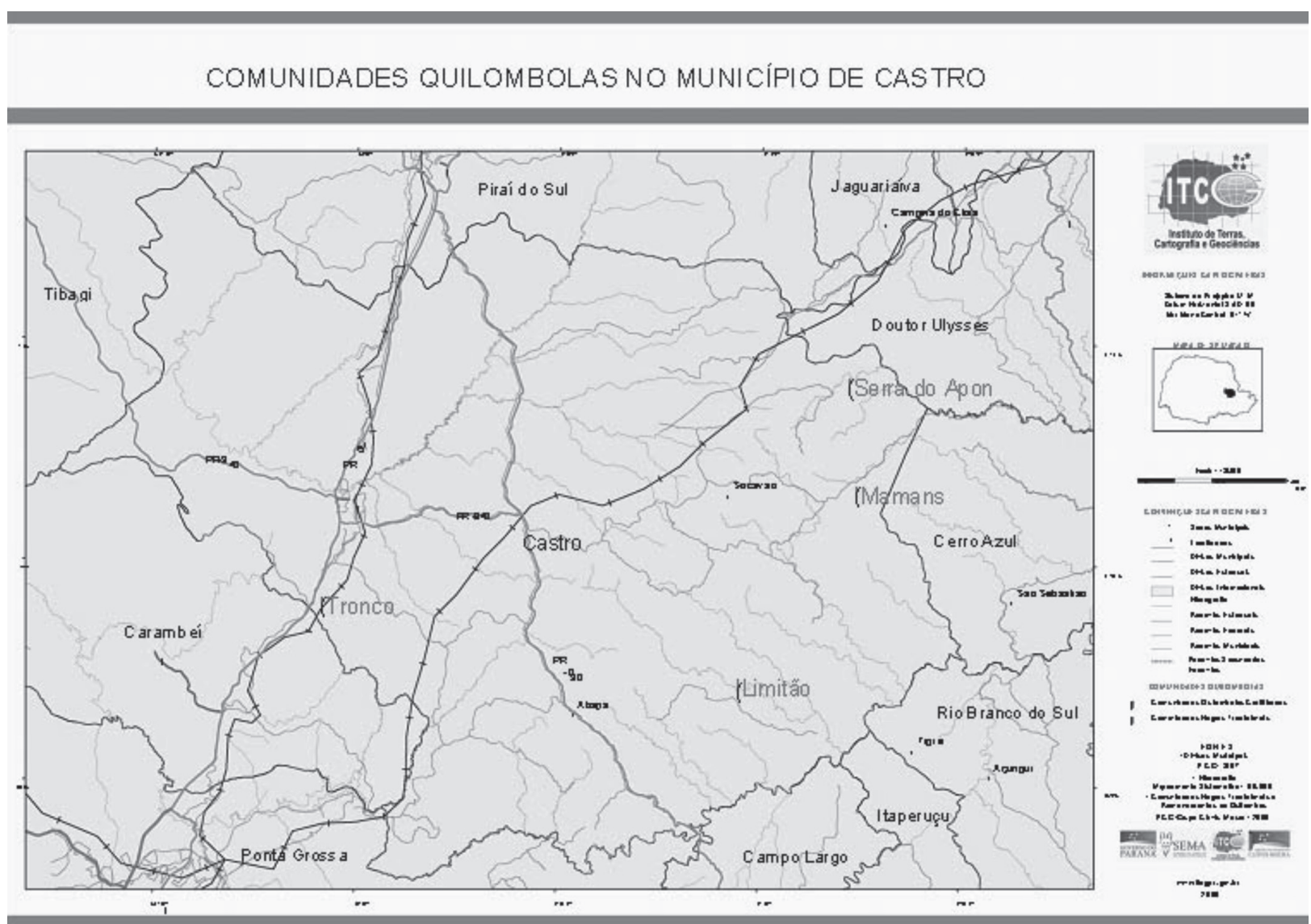

Figura 2 - Comunidades quilombolas no município de Castro/PR

Fonte: Disponível em:< http://www.itcg.pr.gov.br/arquivos/File/quilombolas_2009/CASTRO.pdf>. Acesso em: 25 fev. 2013. 
tações, manifestavam obediência e acreditavam que, como em transe, obtinham da santa a resposta para suas solicitações e preces.

Nessa fazenda, os negros trabalhavam na produção de alimentos e criação de gado, que deviam suprir as necessidades dos moradores e abastecer os conventos carmelitas, no sul de São Paulo. O excedente da produção era vendido em Castro, para adquirir outros produtos como roupas, utensílios e ferramentas de uso da fazenda e dos negros.

Essa situação perdurou por mais de 100 anos (de 1751 a 1864) até que, por iniciativa da ordem religiosa, os padres carmelitas arrendaram a fazenda, com seus escravos, à Casa Comercial Bernardo Gavião Ribeiro e Gavião. De acordo com os Cadernos do Patrimônio (1982, p. 26), "pelo contrato de arrendamento os negros deveriam ser levados para São Paulo", mas os negros já se consideravam livres e não aceitaram pacificamente voltar à escravidão.

Com forte resistência dos negros, os novos proprietários recorreram à ajuda de Curitiba, capital da então Província, que destacou uma força policial para obrigá-los a se entregar aos novos arrendatários da fazenda. Mas, ao se conferir a legitimidade dos documentos referentes aos comprovantes de pagamentos de impostos pela firma paulista, as autoridades perceberam irregularidades que impediam a transferência dos negros da Fazenda Capão Alto para São Paulo, matriz da empresa arrendatária. Nesse impasse, os negros ganharam mais força, convencidos de que as autoridades policiais e fiscais estavam a seu favor. "As autoridades sabiam que a documentação da Casa Comercial Bernardo Gavião Ribeiro \& Gavião não estava em ordem, mas não vacilaram, mesmo assim, em usar a força policial contra os escravos de Nossa Senhora do Carmo". Dessa forma, "a ordem foi mantida e a lei, não" (Cadernos do Patrimônio, 1982, p. 29). Mesmo com os altos impostos que a firma devia à Província, os escravos foram levados para São Paulo. Percebe-se que a preocupação maior das autoridades era evitar que o exemplo dos negros de Capão Alto se tornasse um germe multiplicador de insurreição que poderia se alastrar por toda a Província, numa época em que o movimento abolicionista se fazia presente e ganhava força e adeptos no Paraná e demais regiões do país.

O quilombo de Capão Alto terminou em 1864 e nos registros da época consta que foram levados apenas 23 escravos para São Paulo. Seguindo determinação da Santa "Sinhara", as crianças não deveriam sofrer qualquer tipo de maltrato. Assim, em torno de 100 crianças quilombolas ficaram em Castro e foram distribuídas para famílias, segundo relato do historiador Eduardo Spiller Pena (1999). Os mais de 200 escravos que conseguiram fugir e esconder-se nas redondezas fundaram os principais quilombos da região de Castro, por exemplo, a Serra do Apon, Mamans e Limitão. Outros foram além, até o Rio Grande do Sul.

A Serra do Apon está localizada numa região com relevo alcantilado e vegetação de gramíneas, que servem para o gado. Destacam-se as matas de araucárias e outros tipos de árvores nativas, que se sobressaem em alguns pontos mais altos. Predominam plantações de pinos, áreas mecanizadas, criação de gado em lotes com pequena área rural. Segundo os moradores do lugar, no início do século XX havia uma vegetação abundante, com mata fechada de araucárias e outras madeiras de lei que, com a introdução do agronegócio, foi sendo alterada e reduzida a capões isolados, que podem ser vistos a distância. O Rio Turvo, que margeia o quilombo, tem pouca correnteza, dado o assoreamento provocado em parte pela mecanização e está poluído com agrotóxicos. Comenta-se que os rios eram fundos e serviam para banhos, mas, hoje, é possível atravessá-los a pé em vários pontos.

Atualmente a comunidade Serra do Apon é composta por diferentes grupos étnicos, tais como os poloneses e descendentes indígenas, além da grande maioria de negros. A comunidade possui um espaço social onde as pessoas convivem e tomam decisões, organizam festas e reuniões, garantindo a solidariedade e convivência dos grupos culturalmente constituídos. A comunidade é constituída por 87 pessoas, das quais 49 são adultas e 38 são crianças. Três famílias foram entrevistadas nessa comunidade.

A comunidade quilombola, de uma área originalmente constituída de quase 100 alqueires, tem a posse de aproximadamente quatro alqueires, onde é cultivada a horta e produzidos feijão, milho, mandioca, batata, erva-mate, além da criação de gado vacum e suíno, e aves para o consumo da família. Utilizam vários tipos de ferramentas para o trabalho no roçado, como foice, machado, enxadão e enxada. O excedente da produção é vendido na cidade, para a compra de outros produtos de que necessitam, como sal, açúcar, roupas e remédios.

Segundo relatos dos moradores, a comunidade até a pouco tempo vivia de forma coletiva. Os roçados eram feitos em grupos chamados de puxirão/mutirão, em que todos trabalhavam durante o dia com animadas conversas e cantorias e, ao cair da noite, festejavam com baile, oferecido pelo dono do roçado, em retribuição ao trabalho realizado na lavoura.

Alimentam-se costumeiramente de cuscuz de milho e quirera com carne de porco. A carne de porco é cozida e armazenada com a gordura, para ser utilizada em períodos mais longos e assim manter-se conservada.

Nas entrevistas realizadas, membros da comunidade destacam que, como forma de subsistência, os habitantes negros produzem a esteira de piri e taquara utilizada como leito. Na vila Socavão, distante 20 
km da comunidade Serra do Apon, vendem e trocam parte das esteiras com outros produtos de que necessitam, como tecidos, açúcar, sal, querosene e remédios. Para chegarem à vila, caminham por quase dois dias levando os produtos nas costas, a pé, pelo meio da mata fechada. Isso se repete quando falecem membros da família, que são levados nas costas para serem enterrados no cemitério da vila Socavão.

Ao reportar-se ao tempo, Dona Vani diz que era praxe dormir sobre as esteiras em forma de círculo para serem aquecidos pelo fogo, feito, geralmente, no meio da cozinha. Lembra ainda que, na época, trabalhavam descalços, e teve o primeiro chinelo aos 20 anos de idade. Na maioria das casas o soalho é de chão batido, as paredes de madeira com grandes frestas pelas quais atravessam os ventos frios e chuvas da região. A mobília das casas dos quilombolas é modesta, contando geralmente com o tradicional fogão à lenha de taipa.

O vilarejo da Serra do Apon possui um pequeno comércio e um posto de saúde com atendimento médico e dentário, realizado a cada quinze dias. Existe uma escola municipal de Ensino Fundamental de $1^{\mathrm{a}}$ a $4^{\text {a }}$ séries. Para dar sequência à educação formal, as crianças deslocam-se até Socavão, utilizando o transporte escolar fornecido pela prefeitura do município de Castro. As dificuldades de transporte e mesmo a falta de políticas públicas de educação deixaram as pessoas mais velhas da comunidade sem condições de estudo, de modo que praticamente todos os adultos da comunidade são analfabetos.

As ruas do vilarejo são irregulares, com lamaçais e cascalhos nas partes mais íngremes. Parte da comunidade recebe água tratada, que vem por força da gravidade (fonte localizada em um nível alto, com distribuição em baixo nível). $\mathrm{Na}$ geração anterior, o abastecimento ocorria de forma manual, na fonte ou no riacho. Já a iluminação era com lamparina a querosene e lampião a gás. Há pouco mais de quatro anos a energia elétrica foi distribuída à comunidade.

Muitos tipos de ervas medicinais, como sassafrás, milomen, quina, amargosinho, camomila etc. são utilizados como remédios. A camomila é um ingrediente frequentemente utilizado no preparo do chimarrão. Os moradores mais velhos da comunidade contam que havia ervas nativas para produzir o próprio chimarrão. Hoje, precisam plantar a erva mate.

A religião predominante na comunidade é a católica, tendo como padroeiro São José. As manifestações religiosas são realizadas por novenas e festas ao padroeiro, sendo intensa a veneração a Nossa Senhora Aparecida. Além da religião católica, a comunidade conta ainda com a Igreja Assembleia de Deus.
A comunidade quilombola Serra do Apon foi certificada pela Fundação Cultural Palmares como Remanescente das Comunidades de Quilombos, o que legalmente lhe dá, em tese, o direito de reaver suas terras, fato que se constitui na maior esperança de seus integrantes.

O maior ressentimento manifestado por vários quilombolas da Serra do Apon é a falta de apoio governamental nos momentos em que estavam sendo pressionados, sob todas as formas de violência, para deixar suas terras, fazendo com que um grande número de integrantes dessa comunidade fugisse, abandonando seu pedaço de chão. Os que conseguiram suportar todas essas dificuldades e que permaneceram no local são pessoas que esperam recuperar suas terras. Hoje a maioria das favelas de Castro é formada por pessoas oriundas da expulsão dos quilombos.

\section{Comunidade negra tradicional de São Roque}

Realidade não muito diferente na formação e estrutura ocorre com a comunidade de São Roque, localizada no município de Ivaí, distante vinte quilômetros da sede. Ivaí é um município relativamente novo, tendo se desmembrado de Ipiranga em 10 de junho de 1961. É uma região de planaltos, e a estrada que dá acesso à comunidade é coberta de cascalho e com muitas curvas e declives.

A comunidade de São Roque possui muitas casas de alvenaria e de madeira, com ruas não pavimentadas, um pequeno comércio, com muitas igrejas e um colégio de Ensino Fundamental e Médio com aproximadamente 600 estudantes. A população urbana do bairro é composta por várias etnias, tais como ucraniana, alemã, polonesa e negra, com 38 famílias quilombolas que participam ativamente na comunidade, segundo informações concedidas por Nelson Lourenço. ${ }^{8}$

O senhor Hamilton, ${ }^{9}$ um dos entrevistados para a pesquisa, afirma que São Roque e Rio do Meio eram uma única comunidade, formada por negros. Ocupavam uma faixa extensa de terras, que se estendia desde o Rio São João, passando pela Serra Pedra Branca até a Serra São João. Foram separadas em duas comunidades por causa das ocupações dos imigrantes poloneses, ucranianos e alemães, ocorridas ao longo dos séculos XIX e XX. As terras que eram de posse dos negros foram distribuídas e escrituradas para os agricultores, reduzindo consequentemente sua área. 


\section{COMUNIDADES QUILOMBOLAS EM IVAÍ}

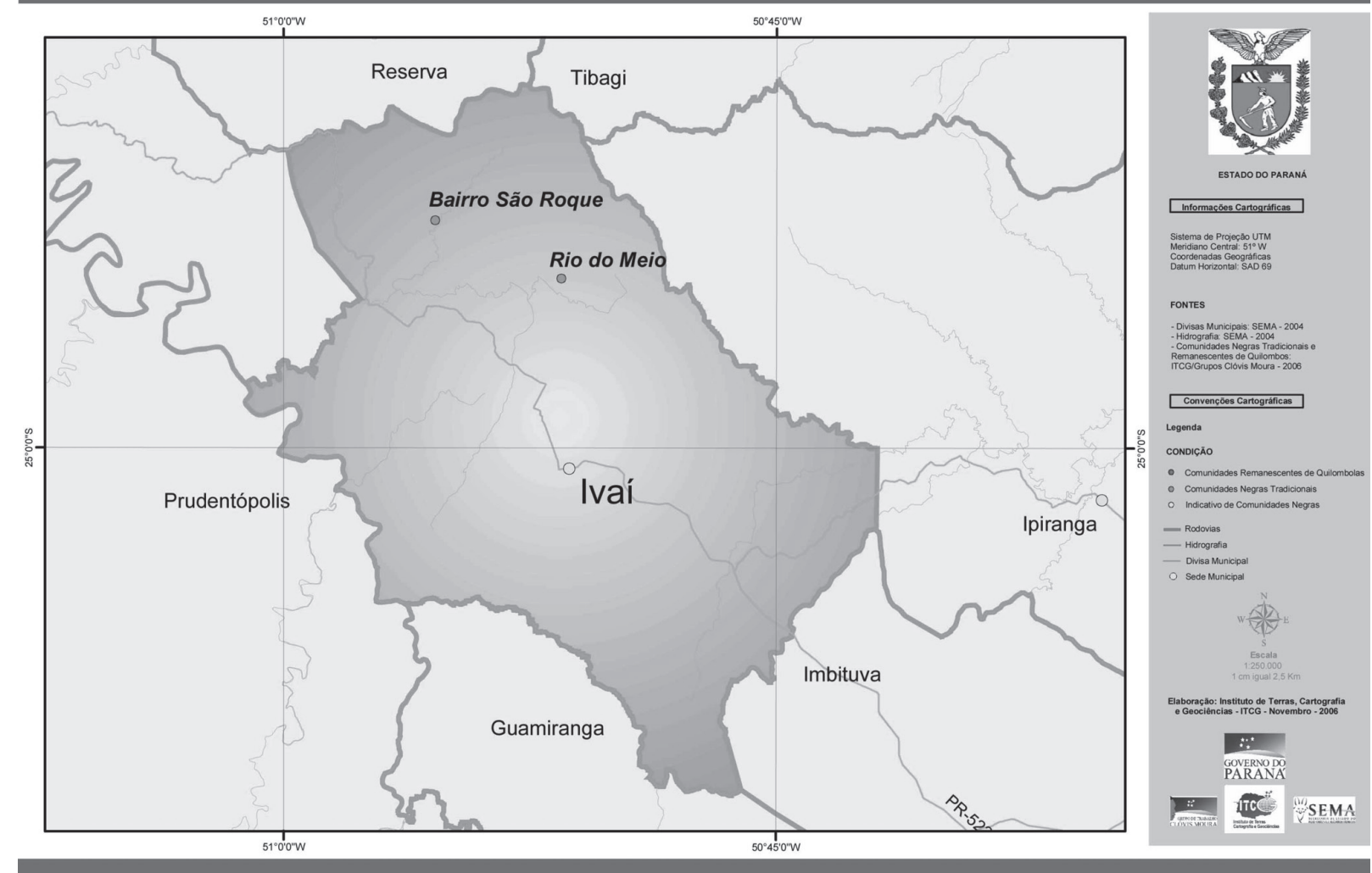

Figura 3 - Comunidades quilombolas do município de Ivaí/PR

Fonte: Disponível em: <http://www.itcg.pr.gov.br/arquivos/File/IVAI.pdf>. Acesso em: 25 fev. 2013.

Segundo informações do senhor Hamilton, as comunidades de São Roque e Rio do Meio remontam ao século XVIII, sendo várias as famílias que compõem o núcleo das duas comunidades, tais como: Lima, Marçal, Ferreira e Lourenço. Como diz o senhor Hamilton, "aqui abriu com os pretos que vieram como cativos, fugindo, porque a liberdade era dos homens ricos, que compravam os negros para trabalhar e era judiado, depois que pegaram a liberdade se esparramou".

O senhor Hamilton, nascido em 1929, é filho de seu Brasílio Ferreira de Lima e Zulmira Ferreira de Lima. Conta que quando sua avó cativa chegou do estado da Bahia, tinha apenas 10 anos, e o dono dessas terras era o negro Paulo Ferreira, que tinha 110 anos. Sua avó casou-se com um dos filhos do negro Paulo Ferreira e da união tiveram 18 filhos, que moravam na localidade do Rio do Meio. A comunidade foi formada desde a época em que os negros cativos se refugiavam das fazendas onde estavam submetidos à escravidão. Os castigos e os trabalhos forçados foram as grandes motivações para as fugas, vindo a tomar posse em terras não tituladas. Há indícios de que índios vivam na região e de que membros da comunidade se casaram com índios. Nelson Lourenço diz que sua bisavó materna "foi capturada, sendo atiçada com cachorro".
O senhor Hamilton conta ainda que seu pai possuía dez alqueires de terra, que as autoridades, alegando inadimplência por não pagar os impostos, entregaram aos "estrangeiros" que assumiram a posse. Diz ainda que "tinha pinhão, tinha tudo, tudo era respeitado, quando veio o município de Ivaí consumiram tudo".

Hoje, membros da comunidade trabalham em outras terras por arrendamento ou porcentagem da colheita, no cultivo de arroz, feijão, milho, mandioca, batata e hortaliças, vendendo o excedente da colheita para adquirir outros produtos de primeira necessidade. A prática do mutirão era frequente durante o período do plantio e da colheita da safra. Já a coleta do pinhão foi extinta junto com a mata fechada de Araucárias Angustifólia e outras espécies, em função do agronegócio.

$\mathrm{Na}$ época dos pais e avós do senhor Hamilton, as casas eram construídas de pau a pique, de pinheiro cortado em lasca. Nas redondezas das casas, os moradores criavam animais soltos nos faxinais, principalmente a criação de cabritos e porcos, que produziam banha e torresmo para serem vendidos na cidade de Ponta Grossa. Ele recorda que seu pai era carreirista apreciador e tocador de cavalos, esporte que envolvia corrida de cavalos em campo aberto. Diferentemente, hoje as brincadeiras que envolvem os jovens e adolescentes da comunidade é o jogo de futebol. 
Hamilton sente-se orgulhoso por ser guardião da chave da Igreja Católica de São Roque, "que existe desde a época dos Ferreira". Nessa igreja, ele guarda com muito carinho o Missale Romanum datado de 1876, escrito em latim, e um quadro de São Roque da época dos seus ancestrais. Destaca ainda que a primeira igreja, que não existe mais no local, foi construída de tábua lascada, com apoio dos afrodescendentes. A comunidade quilombola de São Roque conta ainda com a presença de outros templos religiosos, como a Igreja Evangélica Betel, a Igreja Congregação Cristã no Brasil, a Igreja Evangélica de Confissão Luterana no Brasil, a Igreja Greco-Católica Ucraniana e a Igreja Católica Apostólica Romana.

Até há pouco tempo, as festas religiosas ao padroeiro São Roque eram realizadas em dias diferentes: a Igreja Católica Ucraniana celebrava no dia 15 de agosto e a Igreja Católica Romana no dia 16 do mesmo mês. Segundo Hamilton a festa foi unificada e hoje se realiza no dia 15 de agosto com quermesse, churrasco e leilão, com o envolvimento da maioria dos membros da comunidade. Como de praxe, as pequenas vilas giram em torno das capelas, aliás, como refere o historiador Frank Mezzomo (2002, p. 90), no contexto da colonização no Oeste do Paraná, “a organização social das comunidades ocorre em volta das capelas e escolas, únicos centros donde se promove e organiza a vida comunitária”.

Conta o senhor Hamilton "que nos tempos dos negros na comunidade Rio do Meio, reuniam todas as famílias negras para festejarem, com muita união, ao som do violão e da gaita”. Preparavam alimentos segundo os costumes locais para ofertar aos convidados, utilizando o monjolo para produzir a farinha, a quirera e outros produtos. Era costume também, na comunidade quilombola, a Recomendação das Almas, feita, sobretudo, no período da Quaresma. Em procissão, havia as paradas nas casas, com cantorias e rezas em homenagem aos mortos.

O fogão de taipa de pilão foi muito utilizado nas casas dos negros. Feito com o apiloamento da terra úmida, prensada no local que era construído com a força das próprias mãos, montando-se a estrutura de um fogão com um orifício para colocar a panela de ferro com pé.

O líder da comunidade Nelson Lourenço desabafa dizendo que "os seus pais, avôs eram donos dessas terras e trabalhavam em mutirão, hoje não tem mais as terras, o único espaço é o local de moradia”. Segundo Nelson, as terras foram vendidas e aos poucos ficaram sem nada. ${ }^{10}$ As memórias do líder comu- nitário, ao que parece, buscam reforçar uma história vivida coletivamente. A memória coletiva, no entendimento de Halbwachs (2006), tem como seu atributo mais imediato garantir a continuidade do tempo e permitir resistir ao 'tempo que muda', às rupturas que são inerentes a vida humana. Em suma, a memória constitui um elemento essencial da identidade, da percepção de si e dos outros (Rousso, 2006).

Em 2008, a comunidade obteve a Certificação da Fundação Palmares e, já colhendo os benefícios por esse reconhecimento, receberam computadores do Grupo de Trabalho Clóvis Moura, que estão alojados numa das igrejas da comunidade, por não terem espaço adequado para a instalação. $\mathrm{Na}$ intenção de usar esses computadores em cursos para as crianças, o senhor Nelson solicitou auxílio de uma técnica do Senar, ${ }^{11}$ que desclassificou as máquinas, dizendo serem obsoletas. A comunidade de São Roque conta com a Associação da Comunidade Negra de São Roque que apresenta, entre seus objetivos, a proposição de ações que contribuam para a valorização e afirmação dos direitos dos cidadãos quilombolas.

\section{Considerações finais}

É possível afirmar que novas leituras e perguntas de pesquisas foram extremamente importantes para a compreensão da experiência histórica da escravidão negra: a condição de transporte dos negros da África, a negociação entre senhores e traficantes, o tratamento político e religioso, os reveses da legislação brasileira, os interesses relacionados à escravidão, a formação das comunidades quilombolas no Paraná, bem como as especulações sobre a identidade e legitimidade do acesso à terra do negro remanescente da escravidão. Para a compreensão da experiência histórica da escravidão, a consulta bibliográfica e, sobretudo, a pesquisa de campo foram primorosas.

A experiência da realização do projeto de intervenção pedagógica com as turmas de sextas séries ocorreu no segundo semestre de 2010. Como resultado da implementação, foi possível observar que os estudantes conseguiram estabelecer as relações de lutas e resistências dos negros escravizados em diferentes tempos e contextos sociais. Possibilitou, ainda, uma reflexão mais crítica sobre a contribuição da cultura negra na história e sua importância na formação da sociedade contemporânea. Foram problematizadas as condições de tráfico ocorrido via Atlântico, assim

10. LOURENÇO, Nelson. Entrevista: Morador e líder religioso da comunidade quilombola São Roque. Ivaí, 13 maio 2010. (A/A).

11. O Serviço Nacional de Aprendizagem Rural (Senar) é organizado e administrado pela Confederação Nacional da Agricultura (CNA), nos termos da Lei n. 8.315, de 23 de dezembro de 1991, e do Decreto n 566, de 10 de junho de 1992. Disponível em: <http://www.senar.org.br/ senar/senar_estados.asp?wi=1024\&he=600>. Acesso em: 05 jan. 2013. 
como aspectos das relações de trabalho e fugas em busca de liberdade, formando os quilombos como possíveis espaços sociais de sobrevivência. Novas percepções puderam ser discutidas entre os estudantes do Colégio Estadual Dom Pedro II, onde foi desenvolvido o projeto, como atesta a manifestação de uma aluna quando escreve: "Não sabia que o bisavô do avô do meu avô fosse descendente que veio da África, e que sou uma afro-brasileira". ${ }^{12}$

A utilização de cenas de filmes e documentários, mesmo entendendo ser uma representação da realidade, tornou-se adequado para despertar o interesse dos estudantes para a vivência histórica dos afrodescendentes. Assim, perceberam que os quilombos representavam possibilidade de afirmação de uma identidade cultural, enquanto a posse da terra conferia, de alguma forma, a concretização da liberdade para os negros fugidos ou alforriados. Entenderam, ainda, que os quilombos foram importantes refúgios e permitiram uma alternativa de vida, resistindo às formas e ações a que estavam submetidos dentro da lógica capitalista.

Por fim, pode-se concluir que o resultado da investigação e a discussão promovida com os estudantes permitiram a produção de conhecimentos que podem contribuir com o fazer pedagógico, na medida em que se pauta o famigerado mito da democracia racial e se problematiza a invisibilidade histórica das comunidades quilombolas existentes no Paraná. Diante de toda a situação exposta em relação aos negros, entende-se que cabe também à escola buscar alternativas e metodologias que permitam a compreensão histórica, bem como remediar os inúmeros preconceitos étnicos visíveis e às vezes legitimados no âmbito das instituições.

\section{Referências}

ANJOS, Rafael Sanzio Araújo dos. Quilombos: Geografia Africana, cartografia étnica, territórios tradicionais. Brasília: Mapas Editora \& Consultoria, 2009.

CADERNOS DO PATRIMÔNIO. Fazenda Capão Alto. Secretaria de Estado da Cultura e do Esporte. Coordenadoria do Patrimônio Cultural, 1982.

CHAGAS, Miriam de Fátima. A política do reconhecimento dos "remanescentes das comunidades dos quilombos". Revista Horizontes Antropológicos, v. 7, n. 15, 2001. Disponível em: <http://www.scielo.br/pdf/ha/v7n15/ v7n15a09.pdf>. Acesso em: 05 jan. 2013.

HALBWACHS, Maurice. A memória coletiva. São Paulo: Centauro, 2006.

LIMA, Carlos Alberto Medeiros, Escravos de peleja: a instrumentalização da violência escrava na América Portuguesa (1580-1850). Revista de Sociologia e Política, n. 18, jun/2002.

MEZZOMO, Frank Antonio. Religião, nomos e eu-topia: práxis do catolicismo no oeste do Paraná. Cascavel: Edunioeste, 2002.

MOURA, Gloria. Os quilombos contemporâneos e a educação. Humanidades. Brasília, v. 10, n. 47, nov. 1999.

MUNANGA, Kakingele (Org.). Superando o Racismo na Escola. Brasília: Ministério da Educação, Secretaria de Educação Continuada, 2005.

PENA, Eduardo Spiller. O jogo da face: a astúcia frente aos senhores e à lei na Curitiba provincial. Curitiba: Aos Quatro Ventos, 1999.

ROUSSO, Henry. A memória não é mais o que era. In: AMADO, Janaina; FERREIRA, Marieta de Moraes (Orgs.). Usos E abusos da história oral. 8 ed., Rio de Janeiro: FGV, 2006.
SANTOS, Renato Emerson dos. (Org). Diversidade, espaço e relações étnicos-raciais: o negro na Geografia do Brasil. 2 ed., Belo Horizonte: Gutenberg, 2009.

SCHWARCZ, Lilia Moritz. O Espetáculo das Raças cientistas, instituições e questão racial no Brasil 18701930. São Paulo: Companhia das Letras, 1993.

WACHOWICZ, Ruy. 1939-2000. História do Paraná. 10 ed., Curitiba: Imprensa Oficial do Paraná, 2002.

\section{Figuras e fontes orais}

Comunidades quilombolas no município de Castro/PR. Disponível em: <http://www.itcg.pr.gov.br/arquivos/File/ quilombolas_2009/CASTRO.pdf>. Acesso em: 05 jan. 2013.

Comunidades quilombolas do município de Ivaí/PR. Disponível em: <http://www.itcg.pr.gov.br/arquivos/ File/IVAI.pdf>. Acesso em: 05 jan. 2013.

LIMA, Hamilton Ferreira. Entrevista: Morador da comunidade de São Roque. Ivaí, 13 dez. 2009. (A/A).

LOURENÇO, Nelson. Entrevista: Morador e líder religioso da comunidade quilombola São Roque. Ivaí, 13 maio 2010. (A/A).

LOURENÇO, Nelson. Entrevista: Morador e líder religioso da comunidade quilombola São Roque. Ivaí, 13 dez. 2009. (A/A).

SANTOS, Vani Rodrigues dos. Entrevista: Moradora e líder quilombola Serra do Apon. Castro, 12 dez. 2009. (A/A).

Mapa da população negra e comunidades quilombolas no estado do Paraná. Disponível em: <http://www. diaadia.pr.gov.br/nerea/modules/noticias/makepdf. php?storyid=28>. Acesso em: 05 jan. 2013. 


\title{
Experiencias de esclavitud y formación de comunidades Cimarronas en el estado de Paraná-Brasil
}

\section{Resumen}

En este artículo se analizan dos comunidades cimarronas en la región de Castro y Ivaí, estado de Paraná, Brasil, encuanto a: la experiencia de la esclavitud, el proceso de formación y el estado actual de cada una. Para llevar a cabo la investigación, además de las visitas en el terreno, hemos utilizado fuentes primarias (entrevistas y fotografías) y la literatura. En paralelo, se presentan algunos resultados del trabajo con estudiantes de la escuela primaria, con el fin de contemplar el tema de la cultura afro-brasileña en el plan de estudios, de conformidad con la Ley Federal n. 10.639/2003. La intervención educativa se produjo en una escuela pública ubicada en el municipio de Janiópolis/PR, basado en cursos desarrollados a partir de los datos obtenidos por la investigación.

Palabras clave: esclavitud, comunidades cimarronas, Estado de Paraná.

\section{Experiences of slavery and formation of quilombola communities in}

\section{Paraná-Brazil}

\begin{abstract}
In this article, we analyze two quilombola communities in Castro and Ivaí, State of Paraná, Brazil, regarding to each experience of slavery, formation process and current situation. Observations in loco were conducted, as well as use of primary sources (interviews and photos) and literature review. Moreover, we present some results of work with students of elementary school, in order to attend to Afro-Brazilian culture themes in curriculum, in accordance with Federal Law 10.639/2003. The pedagogical intervention was performed in a public school located in Janiópolis, State of Paraná, Brazil, based on teaching material developed from data obtained through this research.
\end{abstract}

Key words: slavery, quilombola communities, Paraná.

Data de recebimento do artigo: 5/07/2011

Data de aprovação do artigo: 26/11/2012 